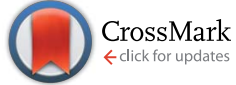

Cite this: RSC Adv., 2017, 7, 16341

\title{
Preparation and dispersity of carbon nanospheres by carbonizing polyacrylonitrile microspheres
}

\author{
Yang Guangzhi, ${ }^{*}$ Yu Binbin, Song Shen, Tang Zhihong, Yu Dengguang \\ and Yang Junhe*
}

Polyacrylonitrile microspheres of about $240 \mathrm{~nm}$ were synthesized and used as a precursor for preparing carbon nanospheres (CNs) by oxidation and sequential carbonization. The relationship between preparation conditions and sphere properties (dispersity and yield) were investigated. For oxidation, a slow heating rate resulted in good dispersity and high final temperature led to high yield of carbon. For carbonization, a slow heating rate and a fast flow rate of protection gas were good for the high dispersity of $\mathrm{CNs}$. Under optimized conditions of $0.1{ }^{\circ} \mathrm{C} \mathrm{min}-1$ to $300{ }^{\circ} \mathrm{C}$ for oxidation and $3{ }^{\circ} \mathrm{C} \mathrm{min}^{-1}$ to $1000{ }^{\circ} \mathrm{C}$ for carbonization under $\mathrm{N}_{2}$ protection of $1.8 \mathrm{~L} \mathrm{~min}{ }^{-1}, \mathrm{CNs}$ with $180 \mathrm{~nm}$ diameter, $4.51 \%$ nitrogen content, high purity, and good dispersity were fabricated. Moreover, after being further treated at $2800{ }^{\circ} \mathrm{C}$, graphitized $\mathrm{CNs}$ with high crystal structures were obtained.

Received 13th December 2016 Accepted 2nd March 2017

DOI: 10.1039/c6ra28129j

rsc.li/rsc-advances not usually uniform. If polymers are first prepared as spheres and then carbonized, the products may have the advantages of good sphere size uniformity and almost no by-products because of the high equality and conversion for polymerization. Moreover, nitrogen-doped carbon materials have many potential uses such as practical environmental applications $^{\mathbf{1 2}}$ and efficient electrode material for supercapacitors ${ }^{13}$ and catalytic materials. ${ }^{14}$ PAN is a type of organic polymer material with high nitrogen content and the content of nitrogen can be controlled by the carbonization temperature; therefore, PAN can be used as a precursor for carbon materials with nitrogen groups. As a good carbon source, polyacrylonitrile (PAN) has long been used as a precursor for carbon fibers and it has also been polymerized as spheres and then carbonized for carbon nanospheres (CNs) of high purity and good uniformity. ${ }^{15}$ After further activation, the porous CNs derived from PAN-based CNs were found to have high-performance as supercapacitors because of their porous carbon structure and presence of a nitrogen group. $^{7}$

However, because PAN has a melting point of $317{ }^{\circ} \mathrm{C}$ and decomposes when heated, deformation of sphere structures and low carbon yield will be inevitable if PAN spheres are directly subjected to carbonization. Furthermore, due to the small sizes of PAN nanospheres, they may aggregate during heat-treatment, making it a challenge to prepare CNs by the carbonization of PAN spheres. Yang et al. ${ }^{15}$ developed a method for coating PAN nanospheres with titanium phosphate, which acts as a protector to separate PAN nanospheres, thus protecting them from aggregation. Yao et al. ${ }^{16}$ reported a homogenous thermal stabilization method to prepare thermally stabilized nanospheres of PAN using an ionic liquid solution. They found
School of Materials Science and Engineering, University of Shanghai for Science and Technology, Shanghai 200093, China. E-mail: yanggzh@usst.edu.cn; jhyang@usst. edu.cn 
that the extent of aggregation of the prepared spheres was closely related to the stabilization conditions.

In this study, PAN spheres were polymerized and carbonized to prepare CNs. Before carbonization, stabilization by oxidation in air was carried out to avoid the deformation of spheres and increase the carbon yield. The relationships between the preparation conditions and sphere properties (dispersity and yield) were mainly investigated. The preferred oxidation and carbonization conditions were proposed and CNs with good dispersity were prepared. The morphology and structure of CNs were also characterized.

\section{Experimental}

\section{Materials and preparation processes}

Acrylonitrile (AN) as the monomer and potassium persulfate (KPS) as the initiator were provided by China National Pharmaceutical Group Corporation. The preparation processes of CNs are shown in Fig. 1. PAN microspheres were prepared by the soapless emulsion polymerization of $30 \mathrm{~mL}$ AN and $30 \mathrm{mg}$ KPS in $300 \mathrm{~mL}$ deionized water. The reaction was held at $65{ }^{\circ} \mathrm{C}$ for $6 \mathrm{~h}$ under the protection of $\mathrm{N}_{2}$ with intensive stirring. The PAN latex was then freeze-dried and stabilized in air under certain conditions of temperature and heating rate. Finally, the oxidized PAN spheres were subjected to carbonization at $1000{ }^{\circ} \mathrm{C}$ for $1 \mathrm{~h}$ under a fixed heating rate and $\mathrm{N}_{2}$ flow rate.

\section{Characterization}

The morphologies of the spheres were investigated via FEI/ Philips XL30 ESEM FEG field emission scanning electron microscopy (SEM). Transmission electron microscopy (TEM) images were obtained via a Hitachi H-8100 TEM system with an accelerating voltage of $200 \mathrm{kV}$. The size distribution and dispersity of the spheres were characterized using a laser diffraction particle size analyzer, the Mastersizer 2000, from Malvern Instruments Ltd., using water as the dispersant. The thermal behavior of PAN spheres was studied by thermogravimetric analysis (TGA, PyrisIand) and differential scanning calorimetry (DSC, using the DSC 8000 from PerkinElmer Company). X-ray diffraction (XRD) patterns of the samples were obtained in the 2-theta range of $10-70^{\circ}$ using a Bruker D8 ADVANCE diffractometer with $\mathrm{Cu} \mathrm{K} \alpha$ radiation. Infrared spectra were acquired using a VERTEX 70 Fourier transform infrared (FTIR) spectrometer (Bruker). Elemental analysis was conducted using the EA2400-II organic element analyzer. The $\mathrm{C}, \mathrm{H}$, and $\mathrm{N}$ contents were analyzed and the $\mathrm{O}$ element content was calculated.

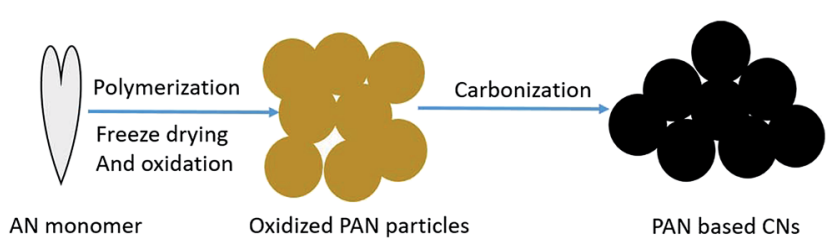

Fig. 1 Preparation processes for $\mathrm{CNs}$.

\section{Results and discussion}

\section{Morphology and thermal behavior of PAN microspheres}

The morphology of the prepared PAN microspheres was characterized by SEM and is shown in Fig. 2. It can be seen that the products are all perfect microspheres with smooth surfaces and they have almost the same diameter, ranging from 230 to $250 \mathrm{~nm}$. The microspheres are also well dispersed, with no aggregation i.e. PAN microsphere structures with good dispersity and uniform size can be obtained by the polymerization of $\mathrm{AN}$ in water.

The thermal behavior of freeze-dried PAN powders was investigated using TGA-DSC in the temperature range of 100$400{ }^{\circ} \mathrm{C}$ under air atmosphere with the heating rates of 3 and $20{ }^{\circ} \mathrm{C} \mathrm{min}^{-1}$. As shown in Fig. 3(a), an obvious weight loss occurred at $250{ }^{\circ} \mathrm{C}$. It can be seen that the decomposition of PAN happened early, but slowly at $3{ }^{\circ} \mathrm{C} \mathrm{min}^{-1}$, and later, but fast at $20{ }^{\circ} \mathrm{C} \mathrm{min}^{-1}$. Fig. 3(b) shows DSC curves with a distinct exothermic peak in the temperature range of $250-400{ }^{\circ} \mathrm{C}$, which is late but strong at $20^{\circ} \mathrm{C} \mathrm{min}^{-1}$ and early but relatively weak at $3{ }^{\circ} \mathrm{C} \min ^{-1}$; moreover, the weight loss varied according to the heating rate. In theory, the weight loss should be less at a low heating rate, whereas in this experiment, the result was contrary; the reason may be that at $20{ }^{\circ} \mathrm{C} \mathrm{min}{ }^{-1}$, the time was quite short and decomposition was not completely carried out. However, according to TGA-DSC, it can be inferred that the heat treatment of PAN in the temperature range of $200-400{ }^{\circ} \mathrm{C}$ greatly affected the stabilization reaction intensity and the yield of CNs. In fact, for the preparation of carbon materials from the PAN precursor, the oxidative stabilization of PAN at temperatures between 200 and $300{ }^{\circ} \mathrm{C}$ is the most critical step of the

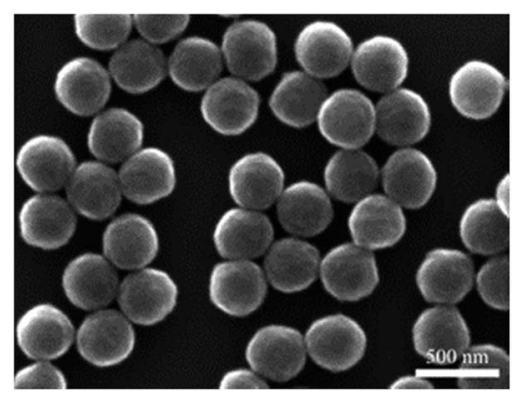

Fig. 2 SEM images of PAN microspheres.
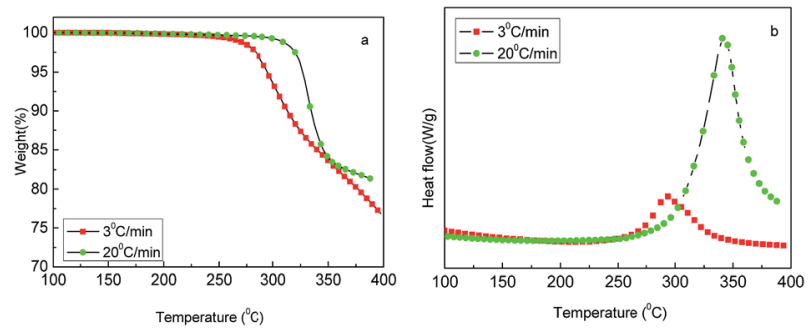

Fig. 3 TGA-DSC profiles of PAN microsphere powders: (a) TG and (b) DSC. 
entire process, which is well known in the field of PAN-based carbon fiber. ${ }^{17}$

\section{Oxidative stabilization of PAN microspheres}

Because of the abovementioned importance of oxidative stabilization, the oxidation factors of heating rate and final temperature were investigated to determine their effects on the dispersity and carbon yield of PAN spheres. The dried PAN powders were subjected to stabilization in an oven with a pump to provide fresh air. As for the heating rate, the powders were heated to the same final temperature of $300{ }^{\circ} \mathrm{C}$ and held for $30 \mathrm{~min}$ at $0.1,0.5,1$, and $3{ }^{\circ} \mathrm{C} \mathrm{min}^{-1}$. The oxidized materials were correspondingly designated as OPAN01300, OPAN05300, OPAN1300, and OPAN5300, according to the heating rate.

Fig. 4 shows the SEM images of PAN spheres oxidized at different heating rates. It can be seen that at slow heating rates of 0.1 and $0.5^{\circ} \mathrm{C} \mathrm{min}^{-1}$ (Fig. 4(a) and (b)), the sphere structure was almost entirely retained after oxidation, whereas at fast heating rates of 1 and $3{ }^{\circ} \mathrm{C} \mathrm{min}^{-1}$ (Fig. 4(c) and (d)), some large particles without spherical morphology were found, which may have been caused by the melting of the spheres. Moreover, aggregation occurred more easily at high heating rates, as seen from the images. Therefore, it can be regarded that a slow heating rate of oxidation is better for maintaining the sphere structure and preventing the melting of the spheres.

Since the morphology of the oxidized PAN particles should be spherical and any melting or aggregation may result in an increase in the particle size, a laser diffraction particle size analyzer was used to investigate the size distribution and then to estimate the dispersity of the spheres. Fig. 5 shows the particle size distribution of the oxidized spheres at different heating rates, and Table 1 presents the statistic diameters of different types. It can be seen from Fig. 5 that all the products have large distributions, up to $10 \mu \mathrm{m}$, indicating large melted particles or the existence of aggregation. In fact, even
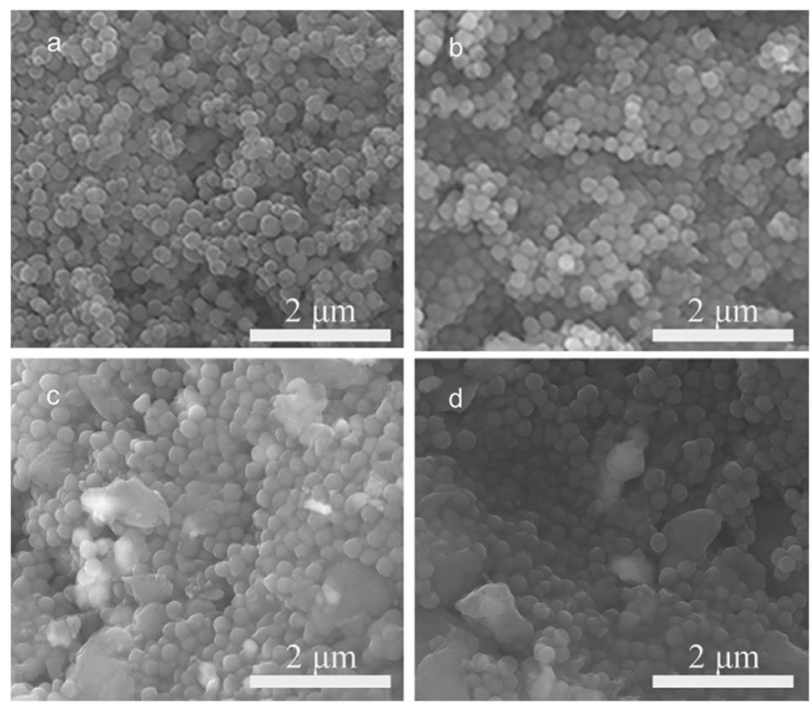

Fig. 4 SEM images of PAN spheres oxidized at different heating rates: (a) 0.1 , (b) 0.5 , (c) 1 , and (d) $3^{\circ} \mathrm{C} \mathrm{min}^{-1}$.

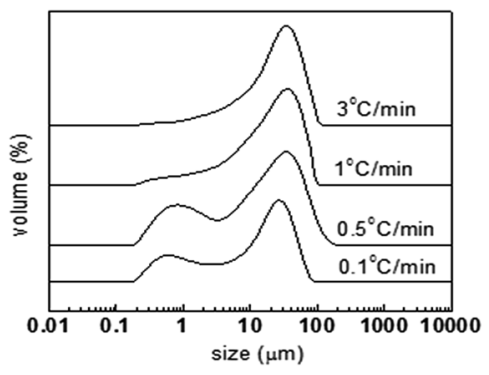

Fig. 5 Particle size distribution of PAN spheres after oxidation at different heating rates.

Table 1 Particle size diameters of PAN spheres after oxidation at different heating rates

\begin{tabular}{lllll}
\hline Samples & $\mathrm{D}[3,2](\mu \mathrm{m})$ & $\mathrm{D}(0.1)(\mu \mathrm{m})$ & $\mathrm{D}(0.5)(\mu \mathrm{m})$ & $\mathrm{D}(0.9)(\mu \mathrm{m})$ \\
\hline OPAN01300 & 2.27 & 0.64 & 15.39 & 45.54 \\
OPAN05300 & 2.46 & 0.72 & 15.70 & 64.04 \\
OPAN1300 & 5.68 & 2.78 & 22.79 & 60.89 \\
OPAN3300 & 8.72 & 4.67 & 26.97 & 63.62
\end{tabular}

nanoparticles with good dispersity may also be found to have large size distribution due to the nanometer level sizes, which easily results in aggregation in the characterization process using the laser diffraction particle size analyzer (this is closely related to the dispersant used). However, it can still be seen that the materials with slow heating rate have greater distributions of small diameters. For OPAN01300 and OPAN05300, a distribution peak below $1 \mu \mathrm{m}$ was found, and these two materials have obviously smaller diameters of $\mathrm{D}[3,2]$ and $\mathrm{D}(0.1)$ as compared to those of OPAN1300 and OPAN3300, which illustrates that a slow heating rate is better for high dispersity.

The powders were heated at the same rate of $0.1^{\circ} \mathrm{C} \mathrm{min}^{-1}$ to different final temperatures of 220,250 , and $300{ }^{\circ} \mathrm{C}$. The oxidized materials were correspondingly designated as OPAN01220, OPAN01250, and OPAN01300 according to the final temperature. Fig. 6 shows the particle size distribution of

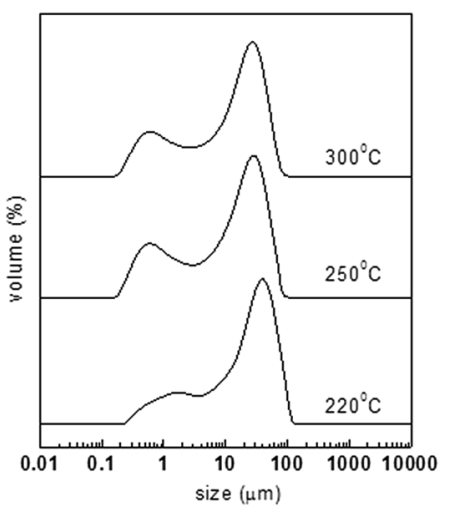

Fig. 6 Particle size distribution of PAN spheres after oxidation at different final temperatures. 
Table 2 Particle size diameters of PAN spheres after oxidation at different final temperatures

\begin{tabular}{lllll}
\hline Samples & $\mathrm{D}[3,2](\mu \mathrm{m})$ & $\mathrm{D}(0.1)(\mu \mathrm{m})$ & $\mathrm{D}(0.5)(\mu \mathrm{m})$ & $\mathrm{D}(0.9)(\mu \mathrm{m})$ \\
\hline OPAN01220 & 4.40 & 1.42 & 25.86 & 68.43 \\
OPAN01250 & 2.12 & 0.60 & 14.46 & 46.77 \\
OPAN01300 & 2.27 & 0.64 & 15.39 & 45.54
\end{tabular}

the oxidized spheres at different final temperatures, and Table 2 presents the statistic diameters of different types. It can be seen that at the final temperature of $220^{\circ} \mathrm{C}$, the materials have more distributions of large diameter than at 250 and $330{ }^{\circ} \mathrm{C}$. This should not be regarded as more melting or chemical crosslinking of spheres because at $220{ }^{\circ} \mathrm{C}$, less heating was required. It should only be inferred that OPAN01220 with small sized spheres tended to physically aggregate during the characterization. From Table 2, it can be seen that the three materials have almost the same magnitude of $\mathrm{D}[3,2]$ and $\mathrm{D}(0.9)$, that is, the final temperature of oxidation had little effect on the dispersity of the spheres in the range from 220 to $300{ }^{\circ} \mathrm{C}$.

Carbon yields of different oxidized PAN spheres were approximately investigated by TGA (Fig. 7) at the heating rate of $5{ }^{\circ} \mathrm{C} \min ^{-1}$ to $800{ }^{\circ} \mathrm{C}$ under $\mathrm{N}_{2}$ protection. The yields for the different processes are shown in Table 3 . It can be seen from Fig. 7(a) that there is little difference in the carbon yield for different oxidation heating rates, as observed via TGA, whereas in Fig. 7(b), the yields of different final temperatures exhibit large differences. As shown in Table 3, with the combination of oxidation and carbonization, the yields of materials oxidized at $300{ }^{\circ} \mathrm{C}$ (OPAN01300, OPAN05300, OPAN1300, and OPAN3300) were higher $(46.5-56.8 \%)$ than those oxidized at 220 and $250{ }^{\circ} \mathrm{C}$
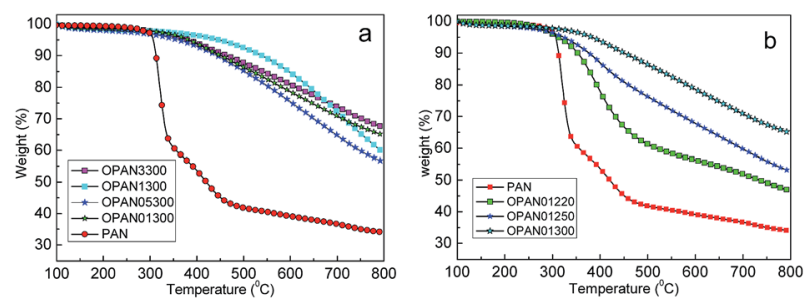

Fig. 7 TGA graphs of PAN spheres oxidized at different heating rates (a) and final temperatures (b).

Table 3 Yield of PAN spheres under different oxidation conditions

\begin{tabular}{llll}
\hline Samples & $\begin{array}{l}\text { Yield of } \\
\text { oxidation }\end{array}$ & $\begin{array}{l}\text { Yield of TG } \\
(\mathrm{wt} \%)\end{array}$ & $\begin{array}{l}\text { Total yield } \\
(\mathrm{wt} \%)\end{array}$ \\
\hline PAN & - & 34.1 & 34.1 \\
OPAN01300 & 79.5 & 65.2 & 51.8 \\
OPAN05300 & 82.0 & 56.7 & 46.5 \\
OPAN1300 & 83.7 & 59.9 & 50.13 \\
OPAN3300 & 84.1 & 67.6 & 56.8 \\
OPAN01220 & 84.9 & 46.9 & 39.8 \\
OPAN01250 & 81.3 & 53.2 & 37.8
\end{tabular}

(37.8-39.8\%), and the yield of PAN without oxidation was only $34.1 \%$, which was very low.

Oxidation is very important for preparing PAN-based carbon materials. During oxidation, the structure of the isolated chain of PAN could transform into a type of cyclization structure via the oxidation, dehydrogenation, and cyclization reactions. ${ }^{\mathbf{1 3 , 1 4}}$ The oxidation of PAN as a carbon fiber precursor has been widely investigated and is often performed in the temperature range of $200-300{ }^{\circ} \mathrm{C}$. Sometimes higher temperatures up to $300{ }^{\circ} \mathrm{C}$ and even up to $400{ }^{\circ} \mathrm{C}$ are suggested for complete stabilization. If the temperature is too high, PAN polymers may be overheated and fuse or even burn. However, if the temperature is too low, the reactions are slow and the stabilization is incomplete, which may result in a low carbon yield. ${ }^{15}$ As for the oxidation of PAN spheres in this study, a slow heating rate can result in good dispersity and a high final temperature can result in a high yield of carbon. The oxidation conditions of OPAN01300 were chosen in the subsequent experiments.

\section{Carbonization of oxidized PAN microspheres}

Carbonization is the last step after polymerization and oxidation. It is often carried out by heat treatment at a high temperature for some time with a certain elevating procedure under inert gas protection. After carbonization, PAN polymers are often transformed into high carbon content, typically, $95 \% ;^{18}$ as for CNs, dispersity and carbon yield are also important for this process. The materials of OPAN01300 were placed in a tubular furnace for carbonization; the heating rate and flow rate of $\mathrm{N}_{2}$ were mainly investigated. The powders were heated to $1000{ }^{\circ} \mathrm{C}$ and held for 60 min under $\mathrm{N}_{2}$ protection of $1.5 \mathrm{~L} \mathrm{~min}^{-1}$ at 3,5 , and $10{ }^{\circ} \mathrm{C} \mathrm{min}^{-1}$. The carbonized materials were correspondingly designated as CPAN3-1.5, CPAN5-1.5, and CPAN101.5 according to the heating rate. As for the $\mathrm{N}_{2}$ flow rate, the powders were heated to $1000{ }^{\circ} \mathrm{C}$ at $5{ }^{\circ} \mathrm{C} \mathrm{min}^{-1}$ and held for 60 min under $\mathrm{N}_{2}$ protection of $1.0,1.5$, and $1.8 \mathrm{~L} \mathrm{~min}^{-1}$. The carbonized materials were correspondingly designated as CPAN5-1.0, CPAN5-1.5, and CPAN5-1.8 according to the flow rate.

The particle size distribution and diameters of carbon spheres after carbonization are shown in Fig. 8 and Table 4, respectively. It can be seen from Fig. 8(a) that for the heating rates of 5 and $10{ }^{\circ} \mathrm{C} \mathrm{min}^{-1}$, more distributions of large sizes
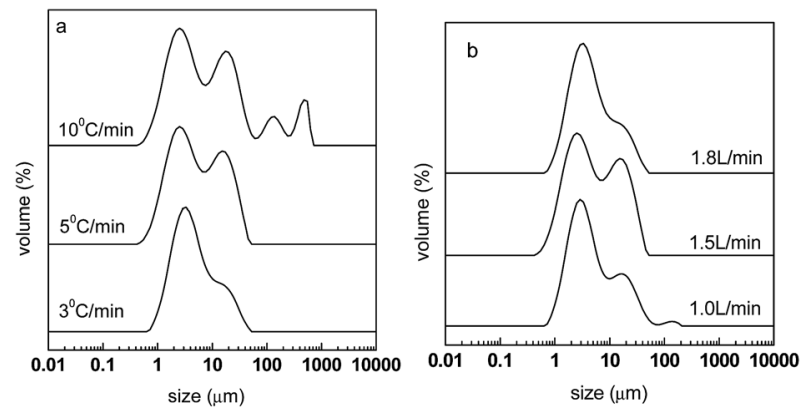

Fig. 8 Particle size distribution of carbon spheres after carbonization at different heating rates (a) and $\mathrm{N}_{2}$ flow rates (b). 
Table 4 Particle size diameters of carbon spheres carbonized under different conditions

\begin{tabular}{lllll}
\hline Samples & $\mathrm{D}[3,2](\mu \mathrm{m})$ & $\mathrm{D}(0.1)(\mu \mathrm{m})$ & $\mathrm{D}(0.5)(\mu \mathrm{m})$ & $\mathrm{D}(0.9)(\mu \mathrm{m})$ \\
\hline CPAN3-1.5 & 2.66 & 1.19 & 3.43 & 12.91 \\
CPAN5-1.5 & 3.43 & 1.48 & 5.03 & 16.63 \\
CPAN10-1.5 & 4.07 & 1.59 & 7.66 & 31.70 \\
CPAN5-1.0 & 3.62 & 1.72 & 4.32 & 14.41 \\
CPAN5-1.8 & 3.62 & 1.77 & 4.38 & 11.38
\end{tabular}

were found, which correspond to large diameter sizes of $\mathrm{D}[3,2]$, $\mathrm{D}(0.9)$, as shown in Table 4. It can be regarded that a fast heating rate is not good for the dispersity of the spheres. Fig. 8 (b) shows that for a $\mathrm{N}_{2}$ flow rate of $1.8 \mathrm{~L} \mathrm{~min}{ }^{-1}$, less distributions of large sizes are found. This is consistent with Table 4, where the materials of CPAN5-1.8 have smaller diameters of $\mathrm{D}(0.5)$ and $\mathrm{D}(0.9)$. Therefore, it can be inferred that a large flow rate of $\mathrm{N}_{2}$ is good for high dispersity, and the reason may be that this could help the emission of decomposed gas and prevent it from participating in cross-linking reactions.

The carbon yields under different carbonization conditions are shown in Table 5. It can be seen that the yields are not very different. The largest yield is $44.3 \%$ for CPAN3-1.5 and the smallest yield is $37.1 \%$ for CPAN5-1.8. It can be inferred that a fast heating rate and slow $\mathrm{N}_{2}$ flow rate are good for high carbon yield.

\section{Preparation and structure of CNs under preferred conditions}

According to the abovementioned research, slow heating rate and high final temperature for oxidation and fast flow rate of protection gas for carbonization are good for high dispersity of PAN-based CNs. Therefore, the preferred conditions were controlled at $0.1{ }^{\circ} \mathrm{C} \mathrm{min}^{-1}$ to $300{ }^{\circ} \mathrm{C}$ for oxidation and $3{ }^{\circ} \mathrm{C} \min ^{-1}$ to $1000{ }^{\circ} \mathrm{C}$ for carbonization under $\mathrm{N}_{2}$ flow of $1.8 \mathrm{~L} \mathrm{~min}^{-1}$.

The morphologies of the prepared CNs as direct powders and dispersed in ethanol were characterized by SEM, as shown in Fig. 9. It can be seen that the sphere morphology of PAN was well retained and the spheres had a good dispersity. After carbonization, the diameter of the spheres decreased from about $240 \mathrm{~nm}$ to about $180 \mathrm{~nm}$.

The FTIR spectra of the prepared CNs are shown in Fig. 10. The $3300-3500 \mathrm{~cm}^{-1}$ region of the infrared spectrum is sensitive to $-\mathrm{OH},-\mathrm{NH}_{2}$, and $-\mathrm{NH}$ vibrations. The absorption peak at $2240 \mathrm{~cm}^{-1}$ belongs to the $\mathrm{C} \equiv \mathrm{N}$ bond stretching vibration of PAN. ${ }^{19}$ The bands at $600-1680 \mathrm{~cm}^{-1}$ are attributed to the $\mathrm{C}=\mathrm{C}$ bond stretching of the CNs, demonstrating the aromatization during the carbonization process. Moreover, the peak at

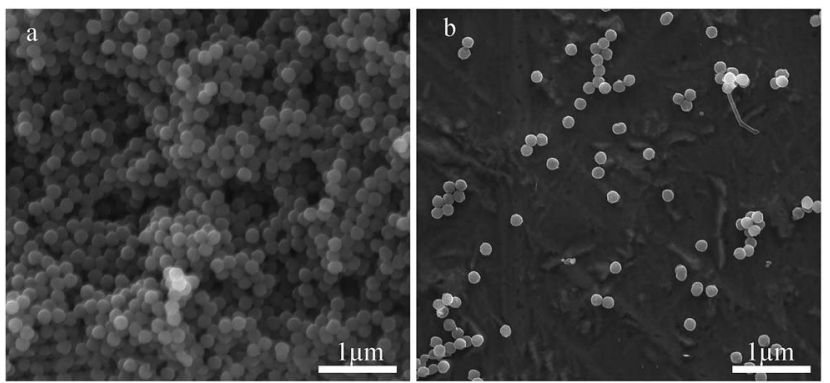

Fig. 9 SEM images of the CNs prepared under optimized conditions: (a) direct observation and (b) dispersed in ethanol.

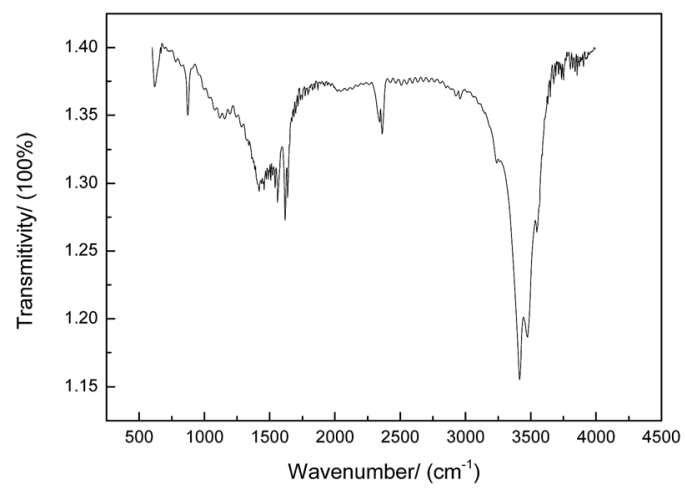

Fig. 10 FTIR spectra of CNs under preferred conditions.

$1460 \mathrm{~cm}^{-1}$ is assigned to the saturated alkyl groups such as $-\mathrm{CH}_{3}$ and $-\mathrm{CH}_{2}$ and the peak at $890-910 \mathrm{~cm}^{-1}$ is due to $=\mathrm{CH}_{2}$. The results of elemental analysis of various states of PAN are shown in Table 6, and it can be seen that the polymerized PAN only contains three elements, $\mathrm{C}, \mathrm{H}$, and $\mathrm{N}$, with the content in good agreement with that in theory. With subsequent oxidation, oxygen is introduced with the content of about $22.95 \%$. After carbonization, the carbon content tends to greatly increase, whereas the contents of other elements tend to largely decrease. Moreover, it was observed that the higher the temperature, the more obvious the trend. The carbon content is about $81.85 \%$ at $1000{ }^{\circ} \mathrm{C}$ and $95.41 \%$ at $1500{ }^{\circ} \mathrm{C}$. The nitrogen content is about $4.51 \%$ at $1000{ }^{\circ} \mathrm{C}$ and $0.05 \%$ at $1500{ }^{\circ} \mathrm{C}$. A cyclization reaction occurs when PAN is oxidized, and nitrogen plays a very important role in cyclization..$^{\mathbf{2}}$

The CNs were also treated at high temperatures of 1500 , 2300 , and $2800{ }^{\circ} \mathrm{C}$. The structures were analyzed by XRD, as shown in Fig. 11. It can be seen that all the materials have the characteristic diffraction profile of carbon at $2 \theta$ of about 260 for the (002) lattice plane and at about 430 for (100). ${ }^{21}$ The peak is broad at low temperature, suggesting a low graphitization

Table 5 Yield of carbon spheres carbonized under different conditions

\begin{tabular}{llllrr}
\hline Samples & CPAN3-1.5 & CPAN5-1.5 & CPAN10-1.5 & CPAN5-1.0 & CPAN5-1.8 \\
\hline Yield of carbonization $(\%)$ & 44.3 & 45.4 & 46.7 & 44.6 & 37.1
\end{tabular}


Table 6 Elemental content for different processes

\begin{tabular}{llrrl}
\hline Element & PAN & OPAN01300 & CPAN3-1.8 & CPAN $\left(1500{ }^{\circ} \mathrm{C}\right)$ \\
\hline $\mathrm{C}(\mathrm{wt} \%)$ & 67.42 & 52.62 & 81.85 & 95.41 \\
$\mathrm{H}(\mathrm{wt} \%)$ & 5.80 & 2.76 & 1.41 & 0.18 \\
$\mathrm{~N}(\mathrm{wt} \%)$ & 26.78 & 21.67 & 4.51 & 0.05 \\
O (calculated, wt\%) & - & 22.95 & 12.23 & 4.36
\end{tabular}

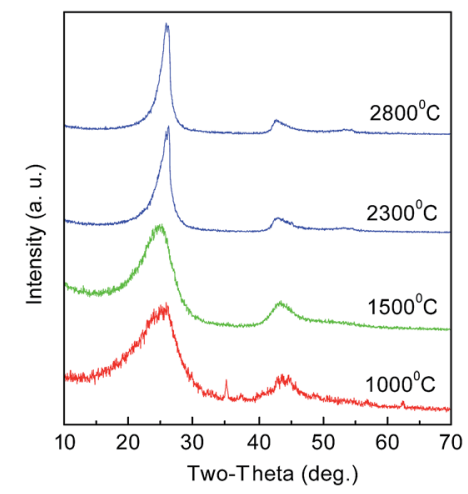

Fig. $11 \mathrm{XRD}$ spectra of $\mathrm{CNs}$ after heat treatment at different temperatures.

degree and the possible presence of amorphous carbon. With the increase in temperature, the (002) peak becomes distinctly sharp and intense, indicating that PAN polymers tend to transform into the graphite crystal structure at high temperature. This trend seems more obvious at $2300{ }^{\circ} \mathrm{C}$, indicating a decreased interlayer spacing of d002 and an increased stacking height of Lc. The TEM images of the products treated at 1000 and $2800{ }^{\circ} \mathrm{C}$ are shown in Fig. 12. When graphitized at $2800{ }^{\circ} \mathrm{C}$, many distinct well-defined regions linking the graphitic layered domains with different orientations could be seen, indicating that many highly graphitized crystal structures were developed.

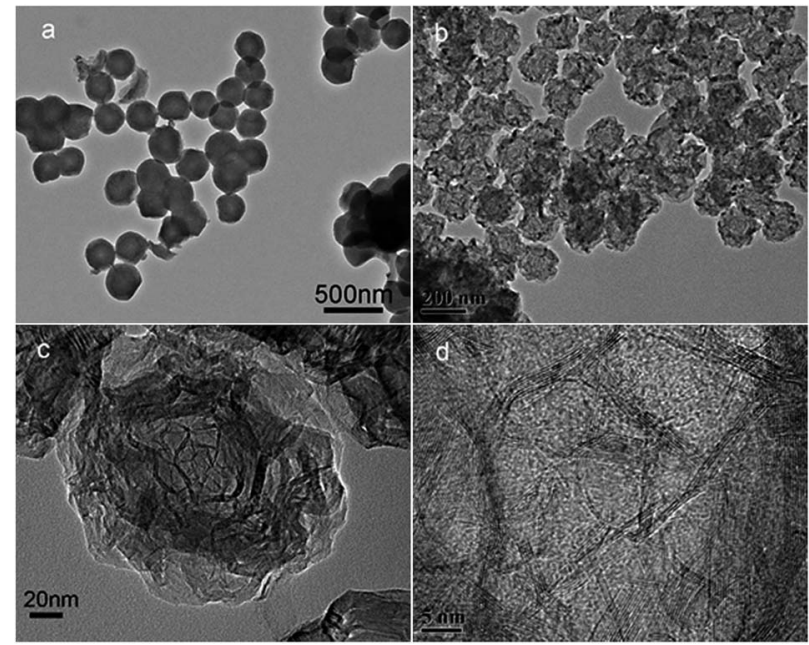

Fig. 12 TEM images of CNs: (a) carbonized at $1000^{\circ} \mathrm{C}$, (b), (c), and (d) graphitized at $2800^{\circ} \mathrm{C}$.

\section{Conclusions}

In this study, PAN microspheres of about $240 \mathrm{~nm}$ were polymerized and used as precursors for CNs preparation. The processes of oxidation and carbonization were mainly studied to determine their effects on the dispersity and carbon yield of the CNs prepared. For oxidation, it was found that a slow heating rate can result in a good dispersity and a high final temperature can result in a high yield of carbon. For carbonization, a slow heating rate and a fast flow rate of $\mathrm{N}_{2}$ were good for high dispersity of CNs. Under optimized conditions of $0.1^{\circ} \mathrm{C}$ $\min ^{-1}$ to $300{ }^{\circ} \mathrm{C}$ for oxidation and $3{ }^{\circ} \mathrm{C} \min ^{-1}$ to $1000{ }^{\circ} \mathrm{C}$ for carbonization under the $\mathrm{N}_{2}$ flow rate of $1.8 \mathrm{~L} \mathrm{~min}^{-1}$, CNs with diameter of $180 \mathrm{~nm}$, high purity, and good dispersity were fabricated. After being further treated at $2800{ }^{\circ} \mathrm{C}$, CNs with highly graphitized crystal structures were obtained.

\section{Acknowledgements}

We gratefully acknowledge the support of the National Science Foundation of China (51102169, 51272157, 51102168), Shanghai Nature Science Foundation (16ZR1423400), and Hujiang Foundation of China (B14006).

\section{References}

1 Q. Liu, G. Qiu, Z. Zhou, J. Li, G. L. Amy, J. Xie and J. Y. Lee, Environ. Sci. Technol., 2016, 50(19), 10596-10605.

2 Y. Liu, J. Xie, C. N. Ong, C. D. Vecitis and Z. Zhou, Opt. Commun., 2015, 1, 769-778.

3 J. L. Li, Z. L. Li, J. H. Tong, C. G. Xia and F. W. Li, RSC Adv., 2015, 5, 70010-70016.

4 Z. G. Jia, Z. Y. Li, S. B. Li, Y. H. Li and R. S. Zhu, J. Mol. Liq., 2016, 220, 56-62.

5 T. Y. Wang, P. Zhao, Q. F. Zhao, B. Wang and S. L. Wang, Drug Delivery, 2016, 23, 420-428.

6 S. C. Ray, Z. N. Tetana, R. Erasmus, A. Mathur and N. J. Coville, Int. J. Energy Res., 2014, 38, 444-451.

7 L. Yao, G. Z. Yang and P. Han, RSC Adv., 2016, 6, 4374843754.

8 Y. J. Qi, M. Zhang, L. Qi and Y. Qi, RSC Adv., 2016, 6, 2081420823.

9 A. Boudjemaa, T. Mokrani, K. Bachari and N. J. Coville, Mater. Sci. Semicond. Process., 2015, 30, 456-461.

10 A. A. Deshmukh, S. D. Mhlanga and N. J. Coville, Food Mater. Sci. Eng., 2010, 70, 1-28.

11 A. Bazargan, Y. Yan, C. W. Hui and G. McKay, Ind. Eng. Chem. Res., 2013, 52, 12689-12702.

12 Y. Liu, L. Yu, C. N. Ong and J. Xie, Nano Res., 2016, 9, 19831993.

13 L. F. Chen, X. D. Zhang, H. W. Liang, M. Kong, Q. F. Guan, P. Chen, Z. Y. Wu and S. H. Yu, ACS Nano, 2012, 6, 70927102.

14 Y. Shao, J. Sui, G. Yin and Y. Gao, Appl. Catal., B, 2008, 79, 89-99.

15 L. C. Yang, Y. Shi, Q. S. Gao, B. Wang, Y. P. Wu and Y. Tang, Carbon, 2008, 46, 1816-1818. 
16 Y. Yao, T. Zhou, T. Yang, R. Xiang and Y. Wu, Carbon, 2013, 58, 249-251.

17 A. Gupta, New aspects in the oxidative stabilization of polyacrylonitrile - based carbon fibers, The Pennsylvania State University, 1996.

18 M. S. A. Rahaman, A. F. Ismail and A. Mustafa, Polym. Degrad. Stab., 2007, 92, 1421-1432.
19 J. C. Meyer, A. K. Geim, M. I. Katsnelson, K. S. Novoselov, T. J. Booth and S. T. Roth, Nature, 2007, 446, 60-63.

20 G. A. Cooper and R. M. Mayer, J. Mater. Sci., 1971, 6, 60-67. 21 Y. Z. Jin, Y. J. Kim, C. Gao, Y. Q. Zhu, A. Huczko, M. Endo and H. W. Kroto, Carbon, 2006, 44, 724-729. 